\title{
Preparation of nanocrystalline cellulose-montmorillonite composite via thermal radiation for liquid-phase adsorption
}

\author{
Shella Permatasari Santoso ${ }^{\mathrm{a}}$, Livy Laysandra ${ }^{\mathrm{b}}$, Jindra Nyoo Putro ${ }^{\mathrm{a}}$, Jenni Lie ${ }^{\mathrm{b}}$, Felycia Edi Soetaredjo ${ }^{\mathrm{b}}$, \\ Suryadi Ismadji a,b,*, Aning Ayucitra ${ }^{\mathrm{b}}$, Yi Hsu Ju ${ }^{\mathrm{a}, *}$ \\ a Department of Chemical Engineering, National Taiwan University of Science and Technology, 106-07 Taipei, Taiwan \\ b Department of Chemical Engineering, Widya Mandala Catholic University, 601-14 Surabaya, Indonesia
}

\section{A R T I C L E I N F O}

\section{Article history:}

Received 12 December 2016

Received in revised form 21 February 2017

Accepted 21 February 2017

Available online 24 February 2017

\section{Keywords:}

Adsorption

Composite

Montmorillonite

Nanocrystalline cellulose

Methylene blue

\begin{abstract}
A B S T R A C T
Nanocrystalline cellulose (NCC) is an excellent binding agent used in various kinds of manufactures. Herein, NCC was used as a binding agent for montmorillonite (MMT) clay before producing composite (NcMMT), which will be utilized as an adsorbent for methylene blue. The morphology of the composite was investigated by using field emission - scanning electron microscopy (FE-SEM) and transmission electron microscopy (TEM), while the characterization was conducted by using Fourier transform infrared spectroscopy (FTIR) and X-ray diffraction (XRD). Two adsorption isotherm models, Freundlich and Langmuir models were used to evaluate the adsorption equilibrium. Adsorption kinetics was assessed by using pseudo-first and second order models. The result indicates that NcMMT is better adsorbent than MMT and NCC; as evidenced by the adsorption capacity $\left(Q_{\mathrm{m}}\right)$ which is $183.8,140.6$ and $96.8 \mathrm{mg} / \mathrm{g}$ (at $60^{\circ} \mathrm{C}$ ) for NcMMT, MMT, and NCC, respectively. The adsorption kinetics was more reasonable described by the pseudo second order.
\end{abstract}

(c) 2017 Elsevier B.V. All rights reserved.

\section{Introduction}

Nanocrystalline cellulose (NCC) is the nano-sized cellulose obtained through the removal of amorphous regions (hemicelluloses) through direct acid hydrolysis of cellulose fibers [1-3]. The removal of amorphous regions causes the crystalline regions to be exposed and encountered a rapid decrease in its degree of polymerization (DP). The decrease in DP triggers the breakdown of cellulose chain, thus producing cellulose with a smaller size or NCC [2]. Compare to cellulose fibers, NCC possesses greater properties such as high surface area, small dimension, and high specific strength $[1,4]$. These excellent properties made NCC potential for many applications such as optical devices [5], regenerative medicine [6], and composite materials [7].

3,7-bis(Dimethylamino)-phenothiazin-5-ium chloride or methylene blue $(\mathrm{MB})$ is a heterocyclic aromatic compound which is conventionally used as a staining agent for animal cells and bacteria [8-11]. Despite its role as popularly used staining agent, MB is also known to be effective in some health applications; for instance, prevention and treatment of fungal infection of freshwater and saltwater fish [12], treatment methemoglobinemia [8] and potassium cyanide poisoning of human [13]. However, MB can be a potentially hazardous material since it is highly soluble in water and easily metabolized in animal tissues $[12,14]$. Accumulation of MB in biological tissues led to serious

\footnotetext{
* Corresponding authors.

E-mail addresses: suryadi@ukwms.ac.id (S. Ismadji), yhju@mail.ntust.edu.tw (Y.H. Ju).
}

health effect due to its carcinogenicity [15-18]. Up to now, adsorption is still the most efficient methods for the environmental recovery from various contaminants $[19,20]$.

Over the years, many studies have been conducted in search of various effective, cheap and environmentally friendly adsorbents [21-23]. Clay minerals are found to be the best candidate and potential adsorbents for the removal hazardous substances [24-26]. Clay minerals are highly demanded adsorbent since they are high adsorptive, low cost and abundant reserve [22]. Montmorillonite (MMT) is one of the clay minerals piled up as the result of the volcanic rocks alteration. MMT is classified as smectite which possess an octahedral layer containing aluminum ions between two tetrahedral silica layers [27,28]. Numerous studies have demonstrated that the adsorption capability of clays can be improved by modifying the surface of clay with synthetic or natural organic substances $[22,23,25]$.

To the best of our knowledge, surface modification of MMT by using NCC to produce composite for the removal of hazardous substances in aqueous solution is still very rare, even though this composite can be a promising new adsorbent. A rapid heating method by microwave thermal radiation was used for composite preparation. This method is quick and efficient compared to the conventional heating method. High energy from the radiation produced by microwave is absorbed and induced rapid heating of MMT and NCC molecules. The heated molecules will move rapidly and collide each other. As a result, the molecules are stranded together to produce a composite. In this work, the adsorption capability of the composite against MB has been evaluated by using two 
well-known adsorption isotherm models namely Langmuir and Freundlich models. The adsorption kinetics also has been evaluated by using pseudo first order and second order models.

\section{Materials and methods}

\subsection{Materials}

MMT clay was obtained from Pacitan, East Java, Indonesia. Analytical grade $\mathrm{MB}\left(\mathrm{C}_{16} \mathrm{H}_{18} \mathrm{~N}_{3} \mathrm{SCl} \cdot 3 \mathrm{H}_{2} \mathrm{O}, 95 \%\right.$ purity, MW $\left.373.90 \mathrm{~g} / \mathrm{mol}\right)$ and sulfuric acid $\left(\mathrm{H}_{2} \mathrm{SO}_{4}, 98 \%\right.$ purity) were purchased from Sigma-Aldrich (Steinheim, Germany). Sodium hydroxide ( $\mathrm{NaOH}, 96 \%$ purity) was provided by Yakuri Pure Chemical (Kyoto, Japan). Sodium chloride ( $\mathrm{NaCl}$, 99.5\% purity) was obtained from Showa Chemical (Tokyo, Japan). The chemicals were directly used as received without any treatment. The water used for dissolving the chemicals was distilled deionized water (resistance $18.3 \mathrm{M} \Omega \cdot \mathrm{cm}$ ).

\subsection{Preparation of NCC}

NCC was produced from the acid hydrolysis of filter paper (Whatman \#1) in $65 \mathrm{wt} \% \mathrm{H}_{2} \mathrm{SO}_{4}$ at $45{ }^{\circ} \mathrm{C}$ for $1 \mathrm{~h}$. Distilled water was added to quench the reaction. The obtained NCC was separated from the acid supernatant by centrifugation (Hettich Zentrifugen EBA-20) at $13,000 \mathrm{rpm}$ for $10 \mathrm{~min}$; centrifugation was repeated for several times until the supernatant reached $\mathrm{pH}$ 5. In this state, supernatant will become turbid since the acid groups on the surface of NCC are washed by water. The loss of acid groups amends surface contact between NCC and water thus NCC become stable in water and remains as suspension. The final suspension was then washed by using dialysis against distilled water. The suspension was solidified in a $-40^{\circ} \mathrm{C}$ refrigerator and then subjected to lyophilization.

\subsection{Preparation of homoionic clay}

MMT was purified from organic impurities by soaking it in hydrogen peroxide for $24 \mathrm{~h}$ and then rinsed several times with distilled water. The wet MMT was dried in an oven at $110^{\circ} \mathrm{C}$ for $24 \mathrm{~h}$. For the preparation of homoionic clay, dried MMT was suspended in $3 \mathrm{M} \mathrm{NaCl}$ solution for $48 \mathrm{~h}$ with constant stirring at a solid to liquid ratio of $1: 10 \mathrm{~g} / \mathrm{mL}$. The suspension and sedimented-solid were separated. The suspension was then collected by centrifugation and washed several times with distilled water to remove excess ions. The resulting MMT was dried at $110{ }^{\circ} \mathrm{C}$ for another $24 \mathrm{~h}$. MMT was then screened with 200 mesh sieve and kept in desiccators before used.

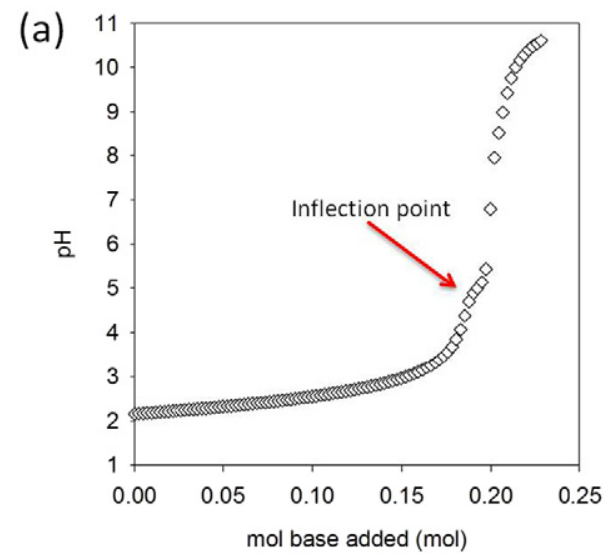

\subsection{Preparation of NCC-MMT composite}

NCC-MMT composite was prepared by mixing the NCC and MMT suspensions. Firstly, NCC suspension $(1 \mathrm{~g} \mathrm{NCC}$ in $100 \mathrm{~mL}$ distilled water) was adjusted to the $\mathrm{pH}$ of 5.0 by using $5 \mathrm{M} \mathrm{NaOH}$. The suspension was allowed to react with $\mathrm{NaOH}$ for $2 \mathrm{~h}$ with a constant stirring. Meanwhile, MMT suspension ( $3 \mathrm{~g}$ MMT in $900 \mathrm{~mL}$ distilled water) was prepared and initially homogenized by ultrasonication for $1 \mathrm{~h}$. MMT suspension was added slowly to NCC suspension with a constant stirring. The mixture was then reacted for $12 \mathrm{~h}$ at $50{ }^{\circ} \mathrm{C}$. Thermal radiation was applied to the mixture for $1.5 \mathrm{~min}$ by microwave (InexTron) at a maximum heating power of $700 \mathrm{~W}$. The intercalated NCC-MMT was then centrifuged to collect the solid, and then dried in an oven at $50{ }^{\circ} \mathrm{C}$ for $24 \mathrm{~h}$ to obtain the composite. All adsorbents used were crushed into powder and sieved with 200 mesh sieve.

\subsection{Potentiometric procedure}

Potentiometric titration was conducted at $25{ }^{\circ} \mathrm{C}$ with a constant ionic strength of $0.1 \mathrm{~mol} \mathrm{dm}^{-3} \mathrm{KCl}$ to a solution containing $0.2 \mathrm{wt} \%$ of NCC in water. Before titration, $0.003 \mathrm{~mol} \mathrm{dm}^{-3} \mathrm{HCl}$ (in $0.1 \mathrm{~mol} \mathrm{dm}^{-3}$ $\mathrm{KCl}$ ) was added to acidify the solution. Carbonate-free $\mathrm{NaOH}$ $0.05 \mathrm{~mol} \mathrm{dm}^{-3}$ in $0.1 \mathrm{~mol} \mathrm{dm}^{-3} \mathrm{KCl}$ (standardized against potassium hydrogen phosphate) was used as the titrant. The titrations were carried out within the $\mathrm{pH}$ range of 2.5 to 11.0 .

\subsection{Adsorbent characterization}

Qualitative analyses were conducted on FTIR Shimadzu 8400 S by using $\mathrm{KBr}$ method in spectra range of $4000-400 \mathrm{~cm}^{-1}$. The patterns of adsorbent powder were characterized by X-ray diffraction (XRD) using a Rigaku Miniflex Goniometer instrument at $30 \mathrm{kV}$ and $15 \mathrm{~mA}$, using Cu $\alpha \mathrm{K}$ radiation. The morphology of the adsorbents was observed by using a JEOL JSM-6500F field emission scanning electron microscope (FE-SEM) with Pt coating at $5.0 \mathrm{kV}$; and by using Tecnai F20 G2 FEI-TEM transmission electron microscope (TEM) at $80 \mathrm{kV}$, the samples were prepared on a 300 mesh Cu grids with $2 \%$ uranyl acetate staining.

\subsection{Adsorption studies}

All the adsorption studies were done in triplicate. Batch adsorption isotherm studies were conducted by adding various amounts of each adsorbent into a series of Erlenmeyer flasks each containing $100 \mathrm{~mL}$ of MB solution with an initial concentration of $200 \mathrm{mg} / \mathrm{L}$. The solutions were shaken in a water bath shaker for $3 \mathrm{~h}$ at three different temperatures $\left(30,45\right.$ and $\left.60{ }^{\circ} \mathrm{C}\right)$. After equilibrium had been reached, the

(b)

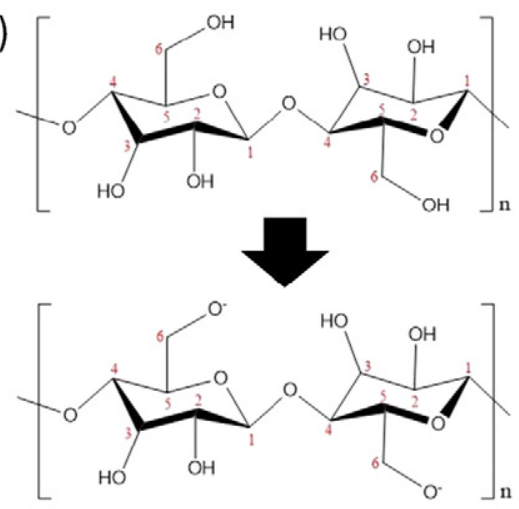

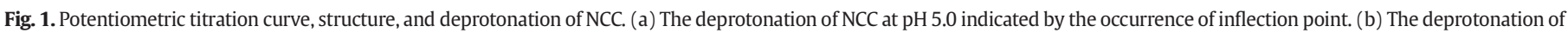
NCC occurred at $C$ number 6 , resulting in the formation of negative charged NCC. 

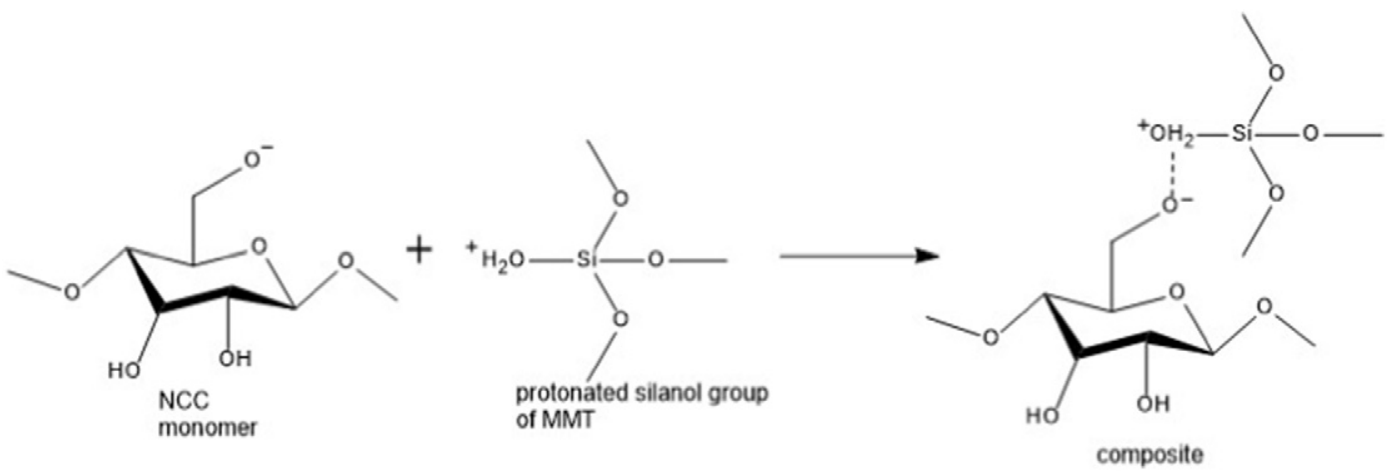

Fig. 2. Proposed formation mechanism of NCMMT, a monomer of NCC and MMT was used to simplify the illustration.

solution was centrifugated at 4500 rpm for $5 \mathrm{~min}$ to separate adsorbent from the supernatant. The concentration of MB was measured in a Shimadzu UV/Vis-1700 spectrophotometer at $664 \mathrm{~nm}$. The percentage of MB removed $(R)$ was calculated by using Eq. (1).

$R=\frac{\left(C_{0}-C_{t}\right)}{C_{0}} \times 100 \%$

where $C_{0}$ and $C_{t}(\mathrm{mg} / \mathrm{L})$ are the concentration of $\mathrm{MB}$ in solution before and after adsorption.

The amount of MB adsorbed at equilibrium was calculated by using Eq. (2).

$Q_{e}=\frac{\left(C_{0}-C_{e}\right) \times V}{m}$

where $Q_{e}(\mathrm{mg} / \mathrm{g}$ adsorbent) is the amount of $\mathrm{MB}$ adsorbed at equilibrium condition, $C_{0}$ and $C_{e}(\mathrm{mg} / \mathrm{L})$ are the concentration of $\mathrm{MB}$ in solution at the beginning and at equilibrium, $V(\mathrm{~L})$ is the volume of $\mathrm{MB}$ solution and $m(\mathrm{~g})$ is the mass of adsorbent used.

Adsorption kinetic studies were studied by adding $0.25 \mathrm{~g}$ adsorbent into a series of Erlenmeyer flask each containing $100 \mathrm{~mL}$ MB solution at various concentrations $(100,200$, and $400 \mathrm{mg} / \mathrm{L})$. The solutions were shaken in a water bath shaker at $30^{\circ} \mathrm{C}$. The sampling of MB was taken at a certain time interval of $30 \mathrm{~min}$ until $300 \mathrm{~min}$. The amount of MB adsorbed at certain time interval was calculated by using Eq. (3).

$Q_{t}=\frac{\left(C_{0}-C_{t}\right) \times V}{m}$

where $Q_{t}$ ( $\mathrm{mg} / \mathrm{g}$ adsorbent) is the amount of MB adsorbed at certain time $t, C_{t}(\mathrm{mg} / \mathrm{L})$ is the concentration of MB at time $t$.

\section{Results and discussion}

\subsection{Formation mechanism of composite}

Negative charged NCC occurs at specific pH condition. The negative charges may promote the intercalation of NCC onto MMT to form a composite (NcMMT). Before finding this effective $\mathrm{pH}$, potentiometric titration was conducted in the solution containing $0.2 \mathrm{wt} \%$ of NCC. As shown from the titration curve in Fig. 1a, an inflection point is occurring at $\mathrm{pH}$ 5.0. This inflection point occurs when the mol base added is adequate to deprotonate H atom of the NCC $[29,30]$. Based on the structure
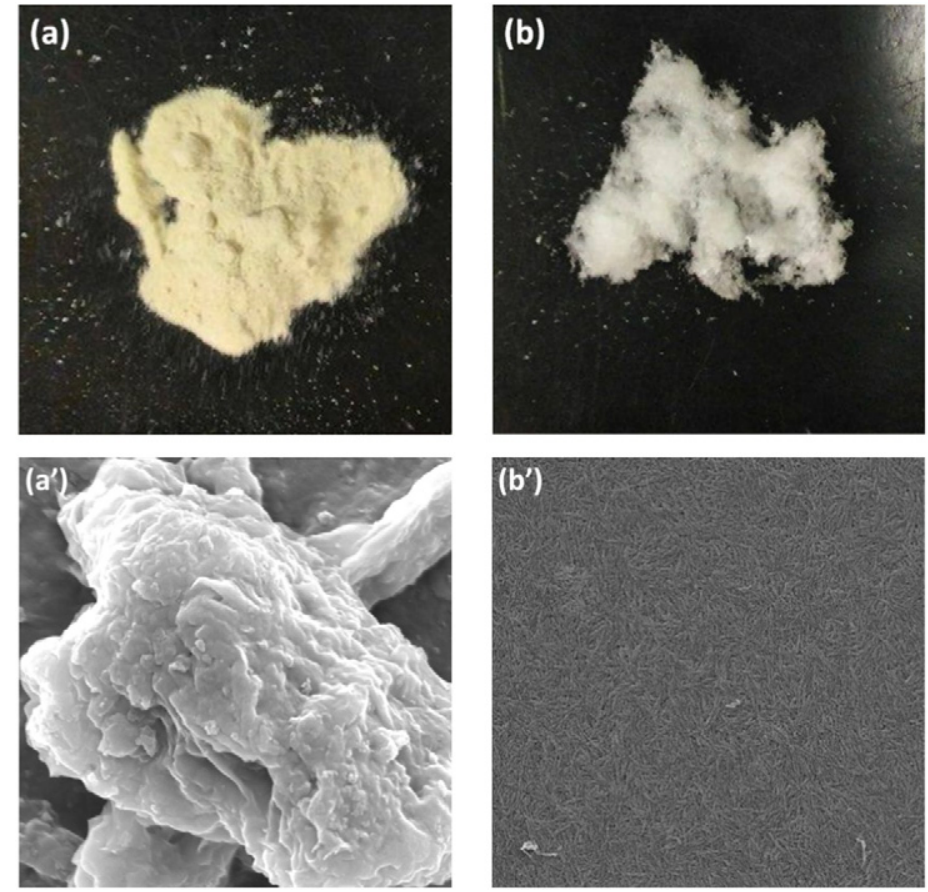
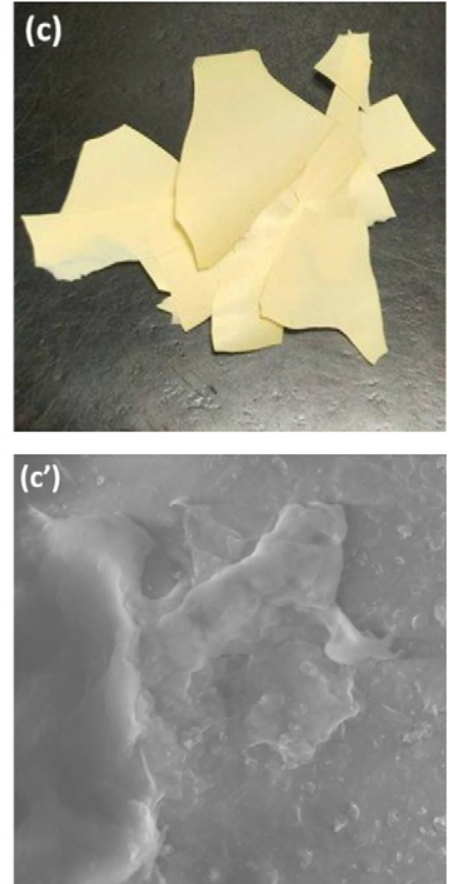

Fig. 3. Solid phase of (a) MMT, (b) NCC and (c) NcMMT. FE-SEM of ( $\left.\mathrm{a}^{\prime}\right)$ MMT, ( $\left.\mathrm{b}^{\prime}\right)$ NCC and ( $\left.\mathrm{c}^{\prime}\right)$ NcMMT at 15.000 magnification and accelerating voltage of $5.0 \mathrm{kV}$. 

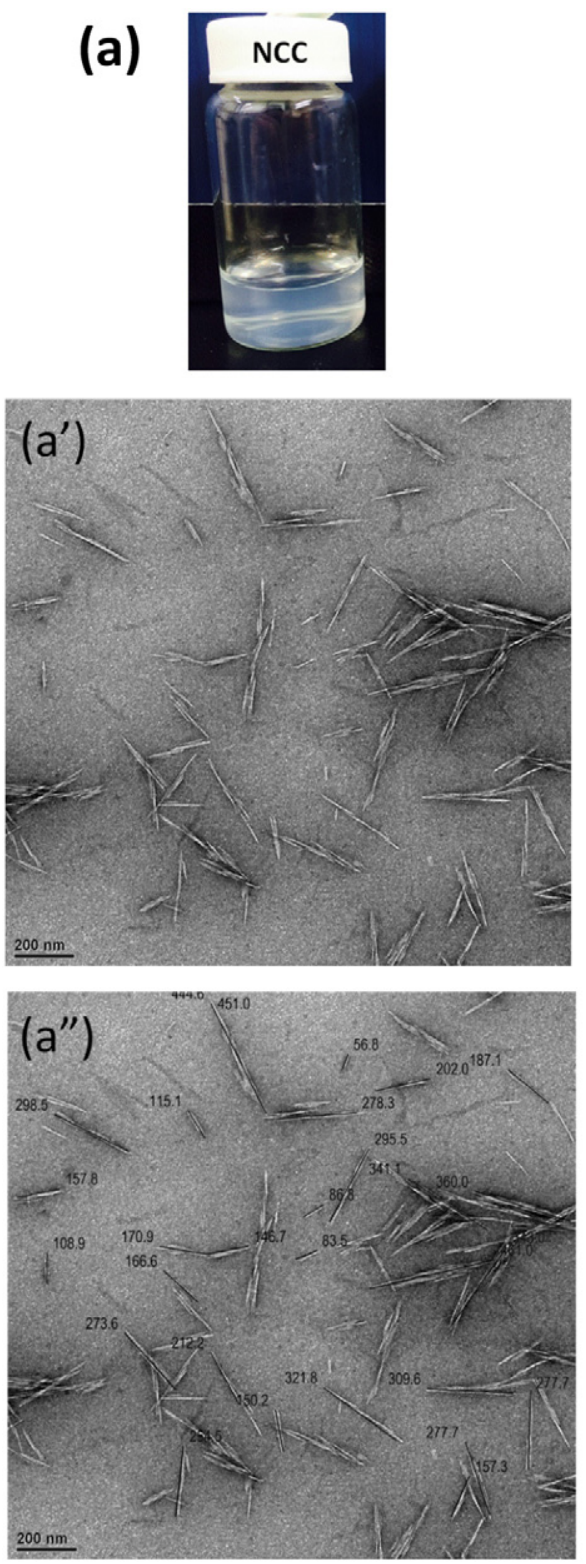
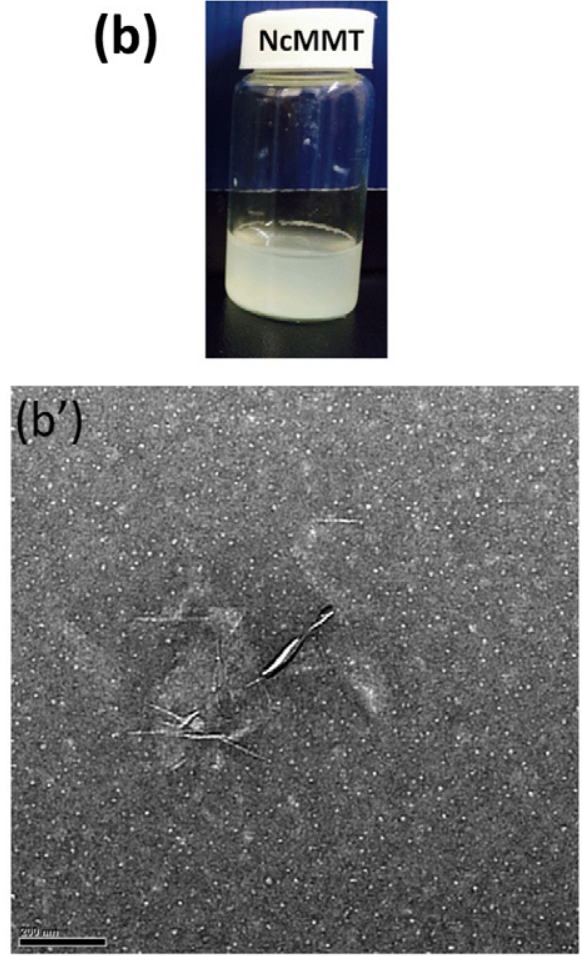

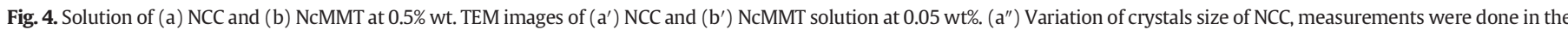
unit of nm.

of NCC, the deprotonation more likely occurred at the $\mathrm{H}$ atom of $\mathrm{CH}_{2} \mathrm{OH}$ group (C6, Fig. 1b). The deprotonation of $\mathrm{H}$ atom caused $\mathrm{CH}_{2} \mathrm{OH}$ group to become charged negatively as $\mathrm{CH}_{2} \mathrm{O}^{-}$.

The alumina octahedral layer (in the center) and two tetrahedral silica layers of MMT are bound together through van der Waals forces [27, 31]. Since van der Waals forces are weak forces, water can easily penetrate and attack the hydroxyl group of the silicate layers thus causing

Table 1

Selected functional groups of NCC.

\begin{tabular}{lll}
\hline Functional groups & & Wavenumber $\left(\mathrm{cm}^{-1}\right)$ \\
\hline O-H & Stretching & 3313 \\
C-H & Stretching & 2895 \\
C=O & Stretching & 1659 \\
C-H & Bending & 1427 \\
C-O & Stretching & 1058 \\
C-H & Wagging & 896 \\
O-H & Out of plane bending & 667 \\
\hline
\end{tabular}

cation imbalance. Further cation imbalance led to the protonation of $\mathrm{OH}$ group in silicate layers and produced positive charges $\mathrm{OH}_{2}^{+}$groups. Henceforward, the addition of negative charged NCC into positively charged MMT promoted the surface charges balancing through the interaction of $\mathrm{CH}_{2} \mathrm{O}^{-}$with the $\mathrm{OH}_{2}^{+}$leading to the formation of composite NcMMT, as proposed in Fig. 2.

Table 2

Selected functional groups of MMT and NcMMT.

\begin{tabular}{llll}
\hline \multirow{2}{*}{ Functional groups } & \multicolumn{2}{l}{ Wavenumber $\left(\mathrm{cm}^{-1}\right)$} \\
\cline { 3 - 4 } & & MMT & NcMMT \\
\hline O-H & Stretching (water molecules) & 3627 & 3630 \\
O-H & Stretching (Si-OH) & 3272 & 3320 \\
O-H & Bending & 1660 & 1633 \\
C-H & Bending & - & 1425 \\
Si-O-Si & Stretching & 1137 & 1038 \\
Al-Al-OH & Bending & 909 & 908 \\
Al-O-Si & Bending & 569 & 522 \\
\hline
\end{tabular}




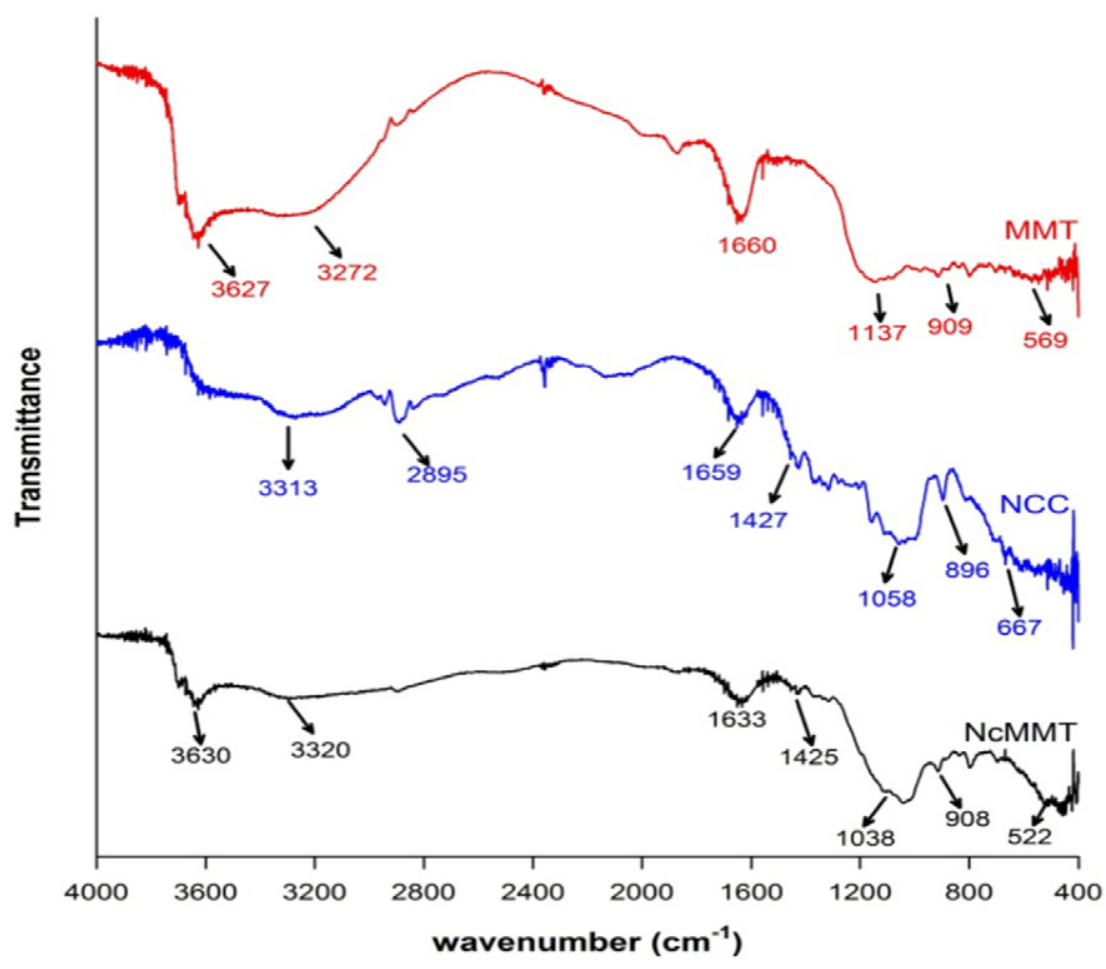

Fig. 5. FTIR spectra of MMT, NCC, and NcMMT measured on $\mathrm{KBr}$ disk at wavenumber $4000-400 \mathrm{~cm}^{-1}$.

\subsection{Characterization of MMT, NCC, and NCMMT}

Field-emission scanning electron microscopy (FE-SEM) was used to study the morphology of the adsorbents at their solid phase. MMT indicates a heterogeneous coarse surface which showed the characteristic of smectite group crystals as shown in Fig. $3 a$ and $a^{\prime}$. Freeze drying process caused fluffy texture of NCC as shown in Fig. 3b, FE-SEM image revealed the needle-like crystals of NCC at the packed structure as shown in Fig. $3 b^{\prime}$. The film of composite NcMMT was produced from the mixture of NCC and MMT suspension. The film was fragile since small sized molecule NCC was used to compose large-sized molecule MMT as shown in Fig. 3c. The surface morphology of NcMMT in Fig. 3c' showed a weakly foliated surface due to the intercalation of NCC onto the surface of MMT.

A recent study by Keshavarzi et al. [32] regarding composite material showed a similar morphology with NcMMT. In their study, composite (CNF-composite) was produced by sonicating the dispersions of

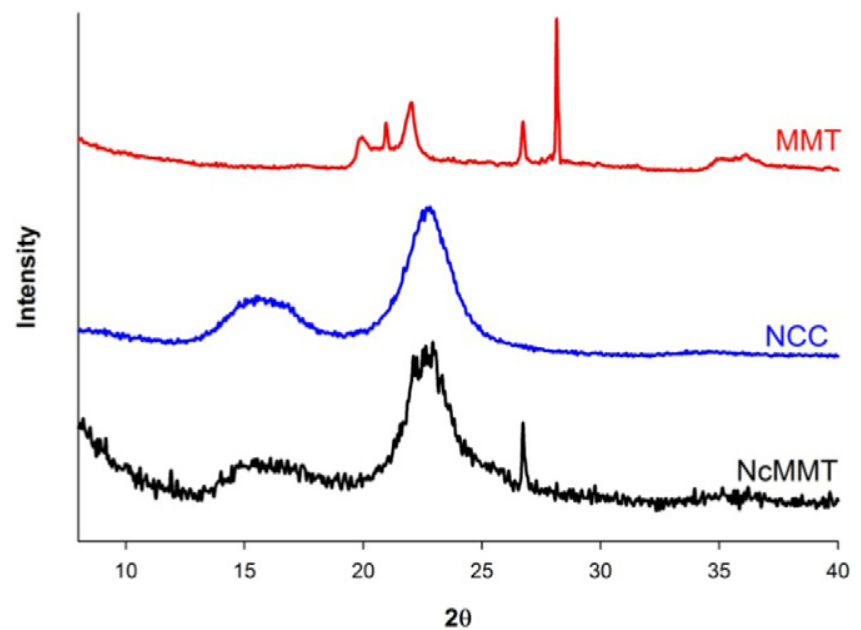

Fig. 6. XRD patterns of MMT, NCC, and NCMMT cellulose nanofibrils (CNF) and zeolite. After drying process, both CNFcomposite and NcMMT are formed into a film. The CNF-composite film is tougher than that of NcMMT film; this is because the cellulose nanofibril used in CNF-composite preparation is having longer size and more elastic compared to NCC. The SEM observation of CNF-composite indicates porous surface. Meanwhile NcMMT surface is smoother. The smooth surface of NcMMT is the result of joining the short sized cellulose, therefore, the space between each cellulose particle is narrow and produced less porous surface.

To clarify the structures of NCC and NcMMT, transmission electron microscopy (TEM) observation was conducted. The stock suspensions of NCC and NcMMT were prepared at $0.5 \mathrm{wt} \%$ as shown in Fig. 4a and $\mathrm{b}$, it is demonstrated that the NCC suspension is in translucent white color while the NcMMT is slightly yellowish. The stock suspensions were then diluted at a dilution factor of 10 to deposit the suspensions as a very thin layer on the TEM grid. $10 \mu \mathrm{l}$ of the diluted solution was placed on the top of glow discharged copper grid. To obtain a good

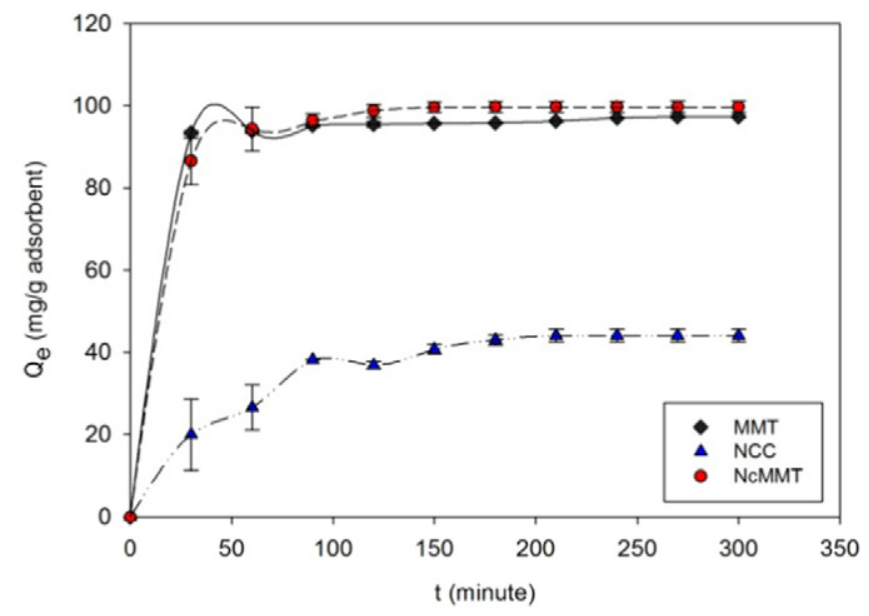

Fig. 7. Effect of contact time on the adsorption of MB by different adsorbents at an initial concentration of $200 \mathrm{mg} / \mathrm{L}$. 

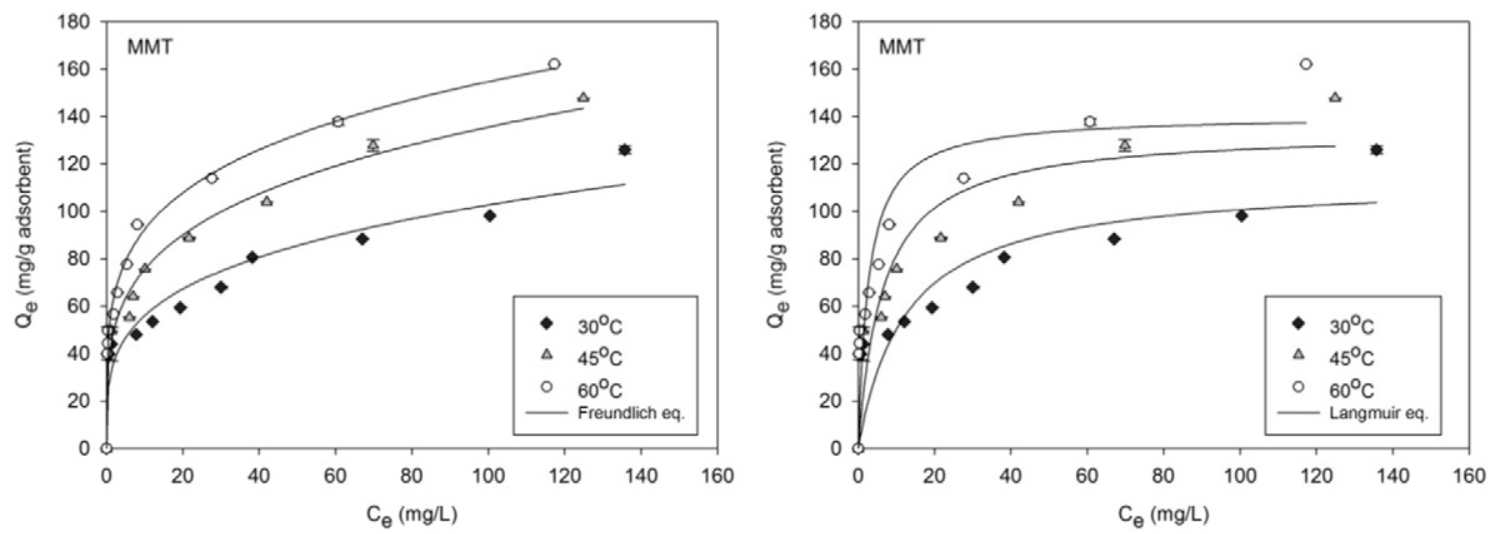

Fig. 8. Adsorption isotherm curves of MB onto MMT with Freundlich and Langmuir fittings.
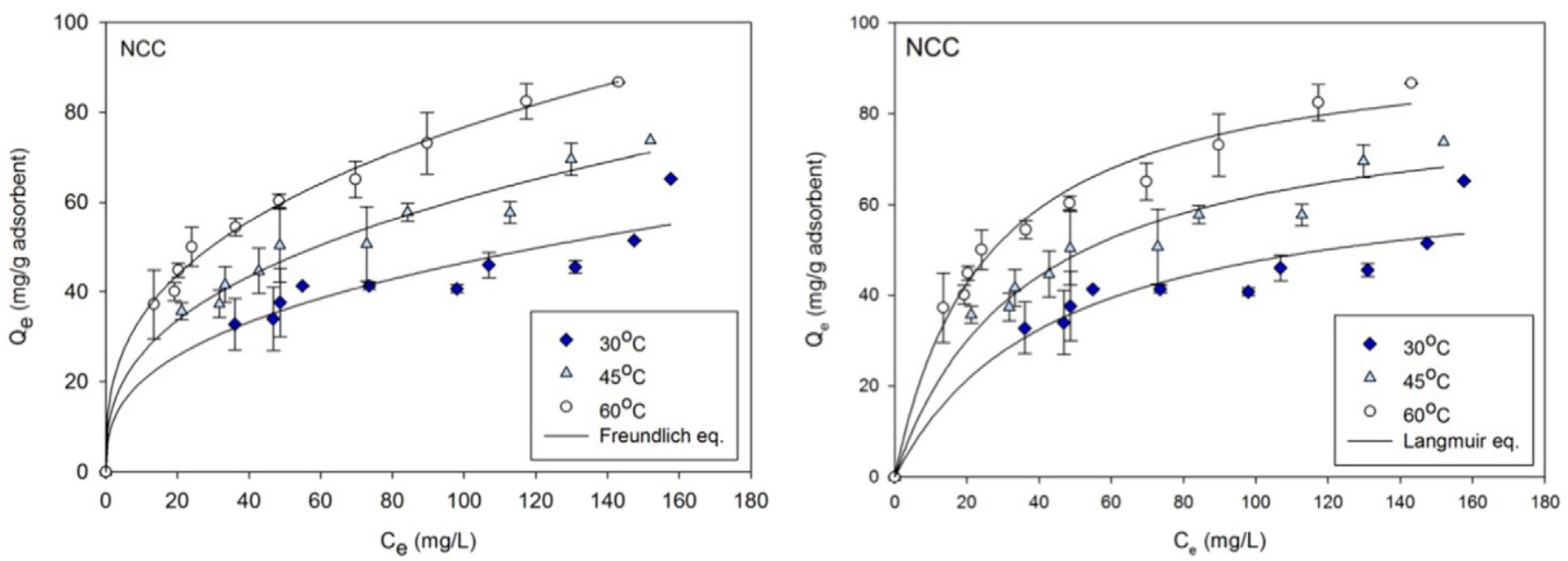

Fig. 9. Adsorption isotherm curves of MB onto NCC with Freundlich and Langmuir fittings.

image resolution, $2 \%$ uranyl acetate was applied on the sample. The staining process was done for $1 \mathrm{~min}$. As shown in Fig. 4a', NCC has a needle-like crystal structure. The NCC crystals size ranged from 56 to $461 \mathrm{~nm}$ as shown in Fig. 4a". As for the composite NcMMT, the powdered NcMMT was suspended in the water prior for TEM observation. The TEM image in Fig. 4b' indicates an event where the molecules of MMT were held by NCC to form NcMMT.

FTIR peaks of NCC are summarized in Table 1 while the spectra of MMT and NcMMT are summarized in Table 2, all the peaks data are

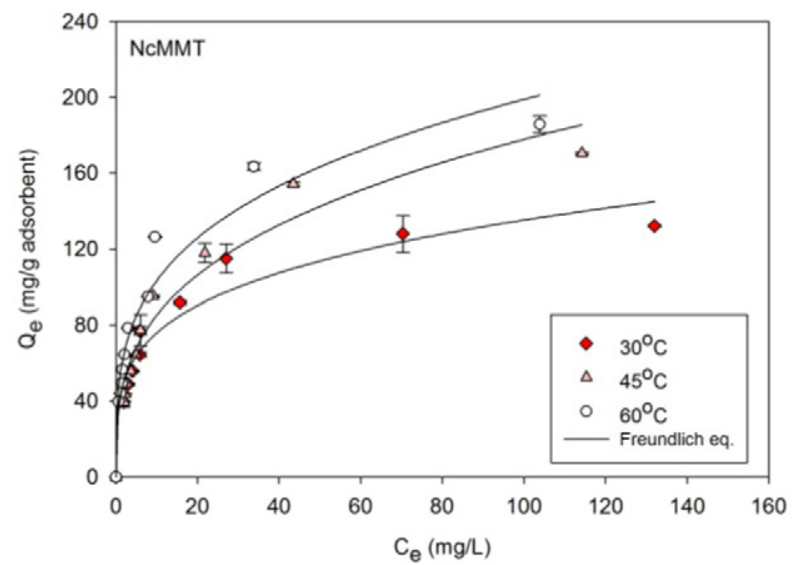

based on information obtained spectrums in Fig. 5. All three spectra possess $\mathrm{O}-\mathrm{H}$ stretch band at $3630-3313 \mathrm{~cm}^{-1}$ which corresponds to the hydroxyl group of water only for NCC, meanwhile for MMT and NcMMT the bands correspond to water molecules and hydroxyl at the silanol groups. The $\mathrm{C}-\mathrm{H}$ bending band at $1425-1427 \mathrm{~cm}^{-1}$ appeared only in NCC and NCMMT indicating the intercalation of NCC into MMT in the formation of composite NcMMT. The other bands of NcMMT shifted slightly compared to those of MMT and NCC. The Si-O-Si band for MMT and NcMMT is different in appearance, where the

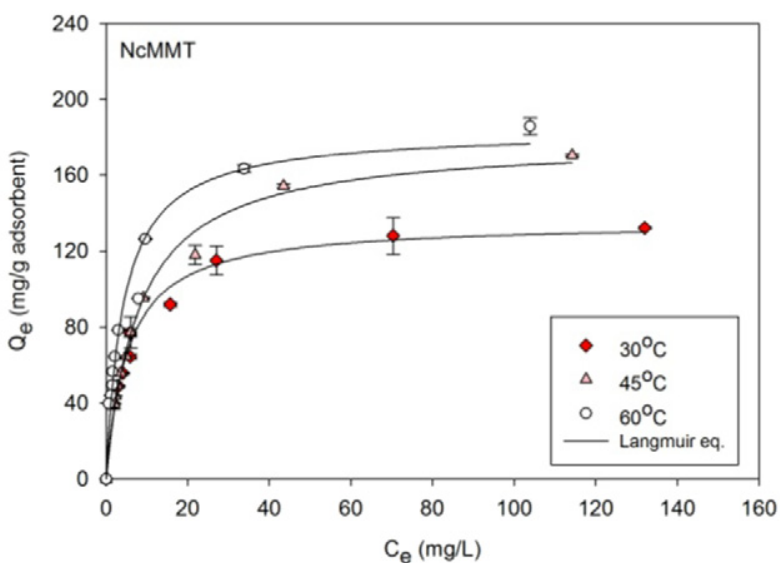

Fig. 10. Adsorption isotherm curves of MB onto NcMMT with Freundlich and Langmuir fittings. 
Table 3

Freundlich and Langmuir adsorption isotherm parameters of MB.

\begin{tabular}{|c|c|c|c|c|c|c|c|c|}
\hline \multirow[t]{2}{*}{$\mathrm{T}\left({ }^{\circ} \mathrm{C}\right)$} & \multicolumn{3}{|c|}{ Freundlich } & \multicolumn{5}{|c|}{ Langmuir } \\
\hline & $K_{\mathrm{F}}$ & $n$ & $r^{2}$ & $K_{\mathrm{L}}$ & $a_{L}$ & $Q_{\mathrm{m}}$ & $R_{\mathrm{L}}$ & $r^{2}$ \\
\hline \multicolumn{9}{|l|}{ MMT } \\
\hline 30 & 30.49 & 3.79 & 0.94 & 9.04 & 0.08 & 113.3 & $5 \times 10^{-4}$ & 0.73 \\
\hline 45 & 42.05 & 3.93 & 0.98 & 20.73 & 0.15 & 134.1 & $2 \times 10^{-4}$ & 0.79 \\
\hline 60 & 55.09 & 4.46 & 0.99 & 52.48 & 0.37 & 140.6 & $9 \times 10^{-5}$ & 0.81 \\
\hline \multicolumn{9}{|l|}{ NCC } \\
\hline 30 & 8.58 & 2.72 & 0.92 & 1.54 & 0.02 & 68.6 & $3 \times 10^{-3}$ & 0.90 \\
\hline 45 & 11.17 & 2.72 & 0.98 & 2.32 & 0.03 & 84.6 & $2 \times 10^{-3}$ & 0.96 \\
\hline 60 & 12.42 & 2.87 & 0.99 & 3.80 & 0.04 & 96.8 & $1 \times 10^{-3}$ & 0.98 \\
\hline \multicolumn{9}{|c|}{ NcMMT } \\
\hline 30 & 40.82 & 3.13 & 0.96 & 22.32 & 0.12 & 178.2 & $2 \times 10^{-4}$ & 0.99 \\
\hline 45 & 42.92 & 4.01 & 0.95 & 26.17 & 0.19 & 134.7 & $2 \times 10^{-4}$ & 0.97 \\
\hline 60 & 53.69 & 3.52 & 0.95 & 43.18 & 0.23 & 183.8 & $1 \times 10^{-4}$ & 0.97 \\
\hline
\end{tabular}

Parameters unit: $K_{\mathrm{F}}(\mathrm{mg} / \mathrm{g}) \cdot(\mathrm{mg} / \mathrm{L})^{1 / \mathrm{n}} ; K_{\mathrm{L}}(\mathrm{L} / \mathrm{g}) ; a_{\mathrm{L}}(\mathrm{L} / \mathrm{mg}) ; Q_{\mathrm{m}}(\mathrm{mg} / \mathrm{g})$.

NcMMT band is stronger than MMT. The strong band transmission of NcMMT is might be due to the stretching of the hydroxyl group in MMT caused by the binding between MMT and NCC.

The diffraction patterns of the powdered MMT, NCC and NcMMT samples are presented in Fig. 6. The diffraction pattern of MMT indicates the presence of quartz at $2 \theta=26.731$ and beidellite at $2 \theta=$ 19.944 and 28.149. The basal spacing $\mathrm{d}(001)$ in MMT could not be observed which is probably due to collapse of the crystallite structure. The collapse was induced by the pretreatment of raw MMT, specifically grinding and the $\mathrm{NaCl}$ submersion process which promotes crystal size reduction [28]. NcMMT, as well as NCC, possessed major peaks at $16.1^{\circ}$ and $22.5^{\circ}$ which indicates 101 and 002 lattice planes [33]. However, the peaks of NcMMT are weaker than that of NCC which is affected by the presence of MMT. The peak of NcMMT at $2 \theta=$ 26.730 is similar to that peak of MMT which indicates the presence of quartz mineral.

\subsection{Adsorption study}

\subsubsection{Effect of adsorption time}

The adsorption of MB onto adsorbents increased with time until equilibrium was reached which represents that the adsorbent has reached its maximum adsorption capacity. The estimation of minimum contact time needed for the system to reach equilibrium condition is an important aspect of designing an effective adsorption process [24]. The effect of contact time on the adsorption of MB by different adsorbents is given in Fig. 7. All curves leveled off as equilibrium was reached. Equilibrium condition of MMT and NcMMT was reached at 120 min of adsorption. At this equilibrium condition, $99.6 \%$ of $\mathrm{MB}$ can be adsorbed by NcMMT while MMT adsorps $95.6 \%$ of MB. Meanwhile, for NCC, longer

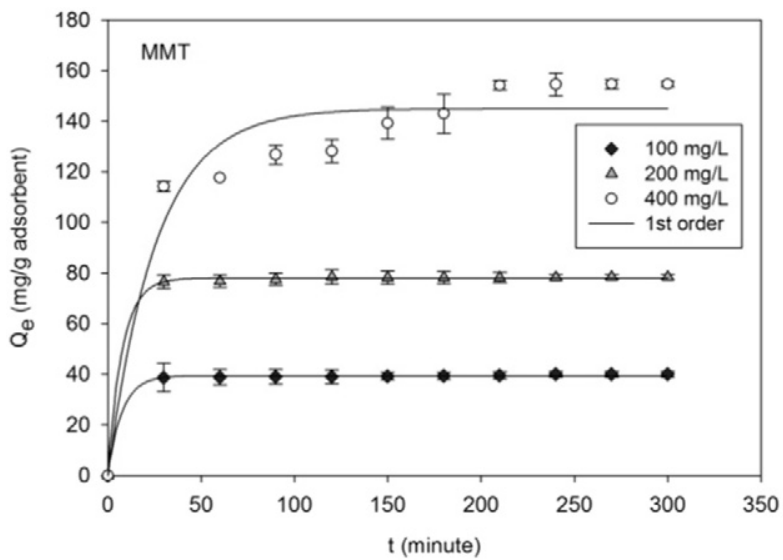

time of $150 \mathrm{~min}$ is needed to reach the equilibrium condition. The percentage of MB that can be removed by NCC at its equilibrium is $42.9 \%$.

\subsubsection{Adsorption isotherm}

The relationship between the amounts of absorbed $\mathrm{MB}$ on the adsorbent $\left(Q_{\mathrm{e}}\right)$ and MB equilibrium concentration in the liquid phase $\left(C_{\mathrm{e}}\right)$ can be conveniently correlated by adsorption isotherm [15]. Two wellknown adsorption equations namely Freundlich [34] and Langmuir models [35] were chosen to describe this relationship. The parameters for both equation models were determined by using non-linear least square fitting. (4)

Freundlich model can be represented by this following equation, Eq.

$$
Q_{e}=K_{\mathrm{F}} C_{\mathrm{e}}^{1 / n}
$$

where $Q_{e}$ is the amount of MB adsorbed per mass of adsorbent $(\mathrm{mg} / \mathrm{g}$ ) and $C_{\mathrm{e}}$ is the equilibrium concentration of $\mathrm{MB}$ in liquid phase $(\mathrm{mg} / \mathrm{L})$. The temperature dependent parameters $K_{\mathrm{F}}$ and $n$ are related to adsorption affinity $(\mathrm{mg} / \mathrm{g})(\mathrm{mg} / \mathrm{L})^{1 / \mathrm{n}}$ and adsorption intensity of the adsorbent, respectively. The constant $n$ also represents the important characteristics of the Freundlich model, where $n>1$ indicates a favorable non-linear adsorption and $n<1$ indicates unfavorable adsorption [22].

Langmuir model can be represented by this following equation, Eq. (5)

$Q_{e}=\frac{K_{\mathrm{L}} C_{\mathrm{e}}}{1+a_{\mathrm{L}} C_{\mathrm{e}}}$

where $K_{\mathrm{L}}$ is related to the maximum adsorption capacity $(\mathrm{L} / \mathrm{g})$ and $a_{\mathrm{L}}$ is related to the net energy of adsorption $(\mathrm{L} / \mathrm{mg})$. The monolayer saturation capacity of the adsorbent for the specific adsorbate can be defined as $Q_{m}$ which is equal to $K_{\mathrm{L}} / a_{\mathrm{L}}(\mathrm{mg} / \mathrm{g})$. The characteristics of Langmuir model can be evaluated from the dimensionless constant $R_{\mathrm{L}}$, determined from Eq. (6)

$R_{L}=\frac{1}{1+K_{\mathrm{L}} C_{0}}$

A favorable adsorption is indicated by $0<R_{\mathrm{L}}<1$ while unfavorable adsorption by $R_{\mathrm{L}}>1$ [36].

MMT was intercalated with NCC through thermal irradiation to enhance its adsorption capacity. MB was used as the adsorbate before analyzing the adsorption capacity of the prepared adsorbents. The adsorption isotherm was conducted, and the data were fitted by using Freundlich and Langmuir models. The adsorption profiles of MMT, NCC, and NcMMT are presented in Figs. 8, 9 and 10, respectively, while the fitting parameters of Freundlich and Langmuir models are summarized in Table 3.

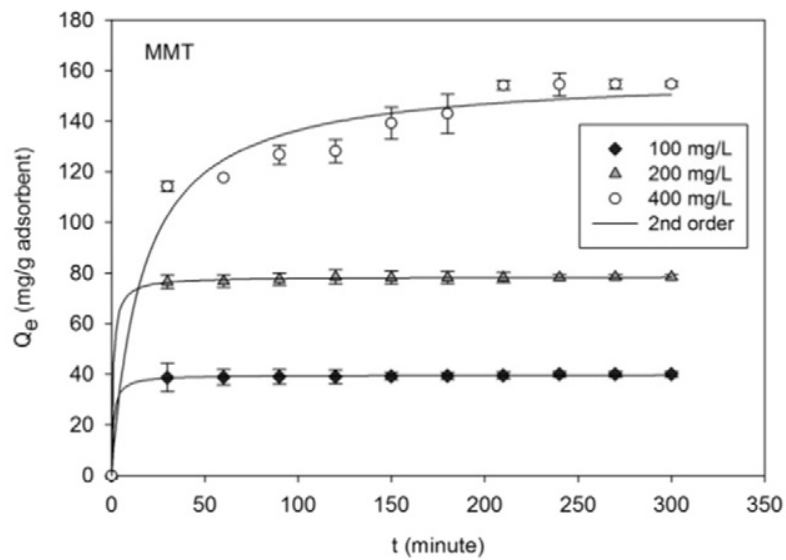

Fig. 11. Adsorption kinetics of MB onto MMT with pseudo first and second order fittings. 

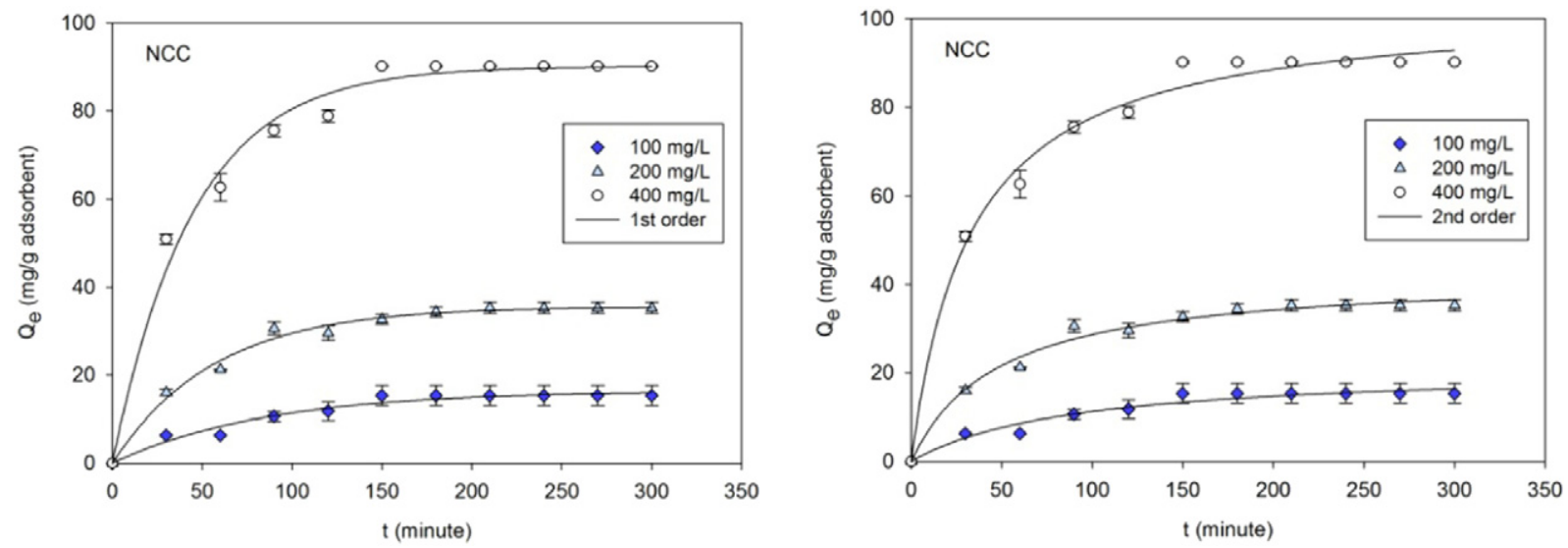

Fig. 12. Adsorption kinetics of MB onto NCC with pseudo first and second order fittings.

The adsorption capacity of the adsorbents is more apparently examined by Langmuir parameter $Q_{\mathrm{m}}$ instead of Freundlich parameter $K_{\mathrm{F}}$. The $Q_{m}$ parameter directly indicates the amount of adsorbate that can be adsorbed per gram of adsorbent, in other word $Q_{m}$ is showing adsorption capacity value. Meanwhile, $K_{\mathrm{F}}$ parameter only indicates the adsorption affinity which expresses the tendency of the adsorbate to adsorb by the adsorbent. The $Q_{m}$ parameter shows that the NcMMT possesses higher adsorption capacity than MMT and NCC, pointing out that NCC promoted the adsorption capacity of MMT. One possible explanation is that NCC widens the surface area and functions like extra hands of MMT thus making the attachment of MB onto surface easier.

Temperature is one of the important factors in adsorption, in which the results indicate that higher temperature promotes the attachment of MB onto the adsorbent. In the case of MMT and NcMMT, since MMT possesses a lattice with positive thermal expansion coefficient, the increase in temperature will promote penetration of adsorbate onto the surface of adsorbent [22,37]. Meanwhile, in the case of NCC, higher temperature leads to faster deprotonation which causes the organic acid compound (NCC) is negatively charged [38,39]. Meanwhile, MB tends to be protonated (positive charged) in solution. The opposite charge of NCC and MB promote the attachment of the two compounds.

\subsubsection{Adsorption kinetics}

Adsorption kinetics modeling can lead to the most suitable estimation of adsorption rate. Lagergren pseudo first-order and pseudo second order models were used to express the adsorption kinetics [40]. The pseudo-first-order equation is given by Eq. (7)

$Q_{t}=Q_{\mathrm{e}}\left[1-\exp \left(-k_{1} t\right)\right]$

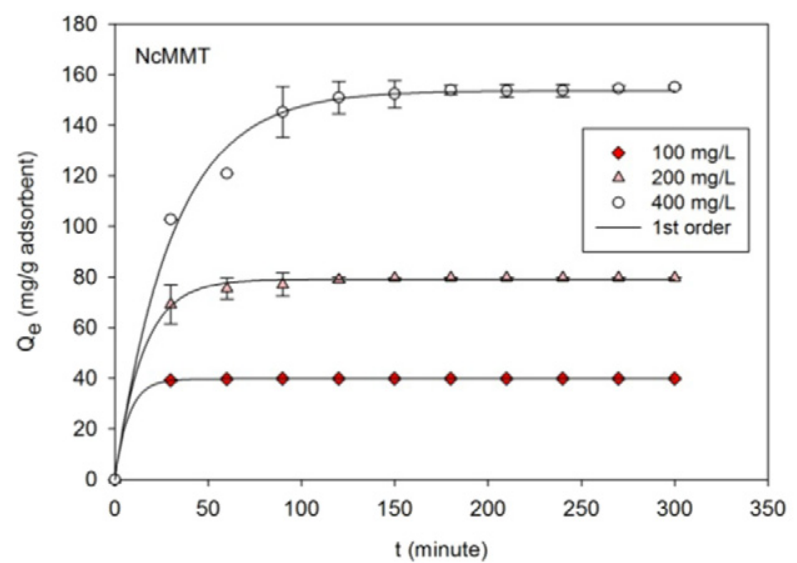

while for pseudo 2nd order the equation is given by Eq. (8)

$Q_{t}=\frac{Q_{\mathrm{e}}^{2} k_{2} t}{1+Q_{\mathrm{e}} k_{2} t}$

where $Q_{t}$ is the amount of MB adsorbed at time $t(\mathrm{mg} / \mathrm{g}), Q_{\mathrm{e}}$ is the adsorption capacity at equilibrium $(\mathrm{mg} / \mathrm{g}), k_{1}$ is the pseudo 1 st order rate constant $(1 / \mathrm{min})$ and $k_{2}$ is the pseudo 2 nd order rate constant (mg/g min).

The adsorption kinetics profiles of MB onto MMT, NCC, and NcMMT with Lagergren pseudo first order and second order fittings are given in Figs. 11, 12 and 13, respectively and the fitting parameters are listed in Table 4. The pseudo first order and pseudo second order plots show good fitting with experimental data. Based on adsorption kinetics studies, pseudo first order rate constant $k_{1}$ usually decreased with increasing initial solute concentration [41]. This can be explained by the higher the initial solute concentration, the longer the time is needed to reach equilibrium. The pseudo second order rate constant $k_{2}$ was also affected by initial solute concentration as the pseudo first order rate constant $k_{1}[22,41]$. Good competency with the theory is obtained from the $k_{2}$ parameter, where $k_{2}$ decreased with increasing initial solute concentration.

It is indicated that initial MB concentration is influenced adsorption process, wherein higher initial MB concentration is leading to higher adsorption of MB. The initial adsorbate concentration provides a driving force that affected mass transfer between the solid phase (adsorbent) and liquid phase (adsorbate) [22]. The increase in initial adsorbate concentration leads to smaller mass transfer resistance thus the mass transfer driving force becomes greater, resulting in higher adsorption of MB.

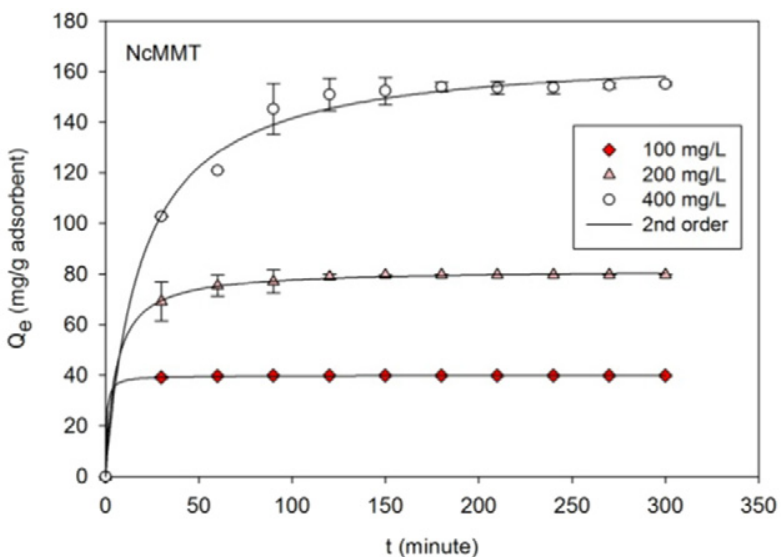

Fig. 13. Adsorption kinetics of MB onto NcMMT with pseudo first and second order fittings. 
Table 4

Pseudo first order and second order parameters for adsorption of MB onto modified H-Ncc and Na-Ncc.

\begin{tabular}{|c|c|c|c|c|c|c|}
\hline \multirow{2}{*}{$\begin{array}{l}\text { MB conc. } \\
(\mathrm{mg} / \mathrm{l})\end{array}$} & \multicolumn{3}{|c|}{ Pseudo first order } & \multicolumn{3}{|c|}{ Pseudo second order } \\
\hline & $Q_{\mathrm{e}}$ & $k_{1}$ & $r^{2}$ & $Q_{e}$ & $k_{2}$ & $r^{2}$ \\
\hline \multicolumn{7}{|l|}{ MMT } \\
\hline 100 & 39.42 & 0.13 & 0.99 & 39.74 & 0.02 & 0.99 \\
\hline 200 & 78.06 & 0.13 & 0.99 & 78.62 & 0.01 & 0.99 \\
\hline 400 & 144.98 & 0.04 & 0.94 & 158.92 & $4 \times 10^{-4}$ & 0.97 \\
\hline \multicolumn{7}{|l|}{ NCC } \\
\hline 100 & 16.44 & 0.0117 & 0.96 & 21.12 & $5.35 \times 10^{-4}$ & 0.95 \\
\hline 200 & 35.55 & 0.0176 & 0.99 & 42.32 & $4.91 \times 10^{-4}$ & 0.98 \\
\hline 400 & 90.12 & 0.0222 & 0.99 & 102.90 & $2.96 \times 10^{-4}$ & 0.99 \\
\hline \multicolumn{7}{|l|}{ NcMMT } \\
\hline 100 & 39.78 & 0.1052 & 0.99 & 40.13 & $1.81 \times 10^{-2}$ & 0.99 \\
\hline 200 & 79.12 & 0.0667 & 0.99 & 81.80 & $2.30 \times 10^{-3}$ & 0.99 \\
\hline 400 & 153.58 & 0.0322 & 0.99 & 168.11 & $3.16 \times 10^{-4}$ & 0.99 \\
\hline
\end{tabular}

\section{Conclusion}

Composite namely NcMMT has been synthesized from the intercalation of NCC onto MMT. The adsorption ability of raw MMT and NCC was compared against that of NcMMT, where methylene blue was used as the adsorbate. Adsorption study, represented by the Langmuir isotherm constant $Q_{m}$ indicates that NcMMT has higher adsorption capacity than that of MMT and NCC. The $Q_{m}$ value at $60{ }^{\circ} \mathrm{C}$ is $183.8,140.6$ and $96.8 \mathrm{mg} / \mathrm{g}$ for NcMMT, MMT, and NCC, respectively. Lagergren pseudo second order model gave more reasonable adsorption kinetics modeling than the pseudo first order.

\section{Acknowledgement}

This work was supported by the National Taiwan University of Science and Technology (RP09-01) and the Widya Mandala Catholic Surabaya Catholic University through a joint research project with contract number RP09-01. The authors thank to Dr. David Barkley for help in English correction.

\section{References}

[1] J. Fan, Y. Li, Maximizing the yield of nanocrystalline cellulose from cotton pulp fiber, Carbohydr. Polym. 88 (2012) 1184-1188.

[2] Y. Habibi, L.A. Lucia, O.J. Rojas, Cellulose nanocrystals: chemistry, self-assembly, and applications, Chem. Rev. 110 (2010) 3479-3500.

[3] M.L. Normand, R. Moriana, M. Ek, Isolation and characterization of cellulose nanocrystals from spruce bark in a biorefinery perspective, Carbohydr. Polym. 111 (2014) 979-987.

[4] B.L. Peng, N. Dhar, H.L. Liu, K.C. Tam, Chemistry and applications of nanocrystalline cellulose and its derivatives: a nanotechnology perspective, Can. J. Chem. Eng. 9999 (2001) 1-16.

[5] J.F. Revol, L. Godbout, D.G. Gray, Solid self-assembled films of cellulose with chiral nematic order and optically variable properties, J. Pulp. Pap. Sci. 24 (1998) 146-149.

[6] K. Fleming, D.G. Gray, S. Matthews, Cellulose crystallites, Chemistry 7 (2001) 1831-1835.

[7] M. Avella, E. Martuscelli, B. Pascucci, M. Raimo, B. Focher, A. Marzetti, A new class of biodegradable materials: poly-3-hydroxy butyrate/steam exploded straw fiber composites, Appl. Polym. Sci. 49 (1993) 2091-2098.

[8] M.I. Greenberg, A review of: "critical care toxicology: diagnosis and management of the critically poisoned patient.", Clin. Toxicol. 43 (2005) 593

[9] B.H. Hameed, A.T. Din, A.L. Ahmad, Adsorption of methylene blue onto bamboobased activated carbon: kinetics and equilibrium studies, J. Hazard. Mater. 141 (2007) 819-825.

[10] J.A. Kiernan, Classification and naming of dyes, stains and fluorochromes, Biotech. Histochem. 76 (2001) 261-278.

[11] L. Wang, X. Pan, F. Wang, L. Yang, L. Liu, Structure-properties relationships investigation on the azo dyes derived from benzene sulfonamide intermediates, Dyes Pigments 76 (2008) 636-645.
[12] R.C. Chen, K.J. Wei, T.M. Wang, Y.M. Yu, J.Y. Li, S.H. Lee, W.H. Wang, T.J. Ren, C.W. Tsai, Simultaneous quantification of antibiotic dyes in aquatic products and feeds by liquid chromatography-tandem mass spectrometry, J. Food Drug Anal. 21 (2013) 339-346

[13] M.M. Brooks, Methylene blue as an antidote for cyanide and carbon monoxide poisoning, J. Am. Med. Assoc. 43 (1933) 585-586.

[14] J.A. Tarbin, D. Chan, G. Stubbings, M. Sharman, Multiresidue determination of triarylmethane and phenothiazine dyes in fish tissues by LC-MS/MS, Anal. Chim. Acta 625 (2008) 188-194.

[15] C.A. Almeida, N.A. Debacher, A.J. Downs, L. Cottet, C.A. Mello, Removal of methylene blue from colored effluents by adsorption on montmorillonite clay, J. Colloid Interface Sci. 332 (2009) 46-53.

[16] H. Cherifi, B. Fatiha, H. Salah, Kinetic studies on the adsorption of methylene blue onto vegetal fiber activated carbons, Appl. Surf. Sci. 282 (2013) 52-59.

[17] S. Gerrard, Methylene blue is dangerous, Br. Med. J. 281 (1980) 1426-1427.

[18] A. Kurniawan, H. Sutiono, N. Indraswati, S. Ismadji, Removal of basic dyes in binary system by adsorption using rarasaponin-bentonite: revisited of extended Langmuir model, Chem. Eng. J. 189-190 (2012) 264-274.

[19] H. Deng, J. Lu, G. Li, G. Zhang, X. Wang, Adsorption of methylene blue on adsorbent materials produced from cotton stalk, Chem. Eng. J. 172 (2011) 326-334.

[20] H. Yan, W. Zhang, X. Kan, L. Dong, Z. Jiang, H. Li, H. Yang, R. Cheng, Sorption of methylene blue by carboxymethyl cellulose and reuse process in a secondary sorption, Colloids Surf. A Physicochem. Eng. Asp. 380 (2011) 143-151.

[21] G. Annadurai, R.S. Juang, D.J. Lee, Use of cellulose-based wastes for adsorption of dyes from aqueous solutions, J. Hazard. Mater. 92 (2002) 263-274.

[22] A. Kurniawan, H. Sutiono, Y.H. Ju, F.E. Soetaredjo, A. Ayucitra, A. Yudha, S. Ismadji, Utilization of rarasaponin natural surfactant for organo-bentonite preparation: application for methylene blue removal from aqueous effluent, Microporous Mesoporous Mater. 142 (2011) 184-193.

[23] A.C. Suwandi, N. Indraswati, S. Ismadji, Adsorption of N-mthylated diaminotriphenilmethane dye (malachite green) on natural rarasaponin modified kaolin, Desalin. Water Treat. 41 (2012) 342-355.

[24] F.A. Banat, B. Al-Bashir, S. Al-Asheh, O. Hayajneh, Adsorption of phenol by bentonite, Environ. Pollut. 107 (2000) 391-398.

[25] A.K. Rahardjo, M.J.J. Susanto, A. Kurniawan, N. Indraswati, S. Ismadji, Modified Ponorogo bentonite for the removal of ampicilin from wastewater, J. Hazard. Mater. 190 (2011) 1001-1008.

[26] J.P. Soetardji, J.C. Claudia, Y.H. Ju, J.A. Hriljac, T.-Y. Chen, F.E. Soetaredjo, S.P. Santoso, A. Kurniawan, S. Ismadji, Ammonia removal from water using sodium hydroxide modified zeolite mordenite, RSC Adv. 5 (2015).

[27] Z. Darvishi, A. Morsali, Synthesis and characterization of nano-bentonite by solvothermal method, Colloids Surf. A Physicochem. Eng. Asp. 377 (2011) 15-19.

[28] C. Volzone, L.B. Garrido, Changes in suspension properties of structural modified montmorillonites, Ceramica 47 (2001) 4-8.

[29] S.P. Santoso, A.E. Angkawijaya, S. Ismadji, A. Ayucitra, F.E. Soetaredjo, P.L.T. Nguyen, Y.H. Ju, Complex formation study of binary and ternary complexes including 2,3dihydroxybenzoic acid, $\mathrm{N}$-acetylcysteine and divalent metal ions, J. Solut. Chem. 45 (2016) 518-533.

[30] T.T.D. Nguyen, S.P. Santoso, T.T.B. Nguyen, A.E. Angkawijaya, P.L.T. Nguyen, Y.H. Ju, Solution equilibrium study of divalent metal ions with phenylpropanoid derivatives and acetylcysteine ligands, Chem. Pharm. Bull. 64 (2016) 1560-1569.

[31] Q.H. Hu, S.Z. Qiao, F. Haghseresht, M.A. Wilson, G.Q. Lu, Adsorption study for removal of basic red dye using bentonite, Ind. Eng. Chem. Res. 45 (2006) 733.

[32] N. Keshavarzi, F.M. Rad, A. Mace, F. Ansari, F. Akhtar, U. Nilsson, L. Berglund, L Bergström, Nanocellulose-zeolite composite films for odor elimination, Appl. Mater. Interfaces 7 (2015) 14254-14262.

[33] S. Park, J.O. Baker, M.E. Himmel, P.A. Parilla, D.K. Johnson, Cellulose crystallinity index: measurement techniques and their impact on interpreting cellulase performance, Biotechnol. Biofuels 3 (2010) 10

[34] H. Freundlich, Of the adsorption of gases. Section II. Kinetics and energetics of gas adsorption. Introductory paper to section II, Trans. Faraday Soc. 28 (1932) 195-201.

[35] I. Langmuir, The constitution and fundamental properties of solids and liquids. Part I. Solids, J. Am. Chem. Soc. 38 (1916) 2221-2295.

[36] E.K. Putra, R. Pranowo, J. Sunarso, N. Indraswati, S. Ismadji, Performance of activated carbon and bentonite for adsorption of amoxicillin from wastewater: mechanisms, isotherms and kinetics, Water Res. 43 (2009) 2419-2430.

[37] A.S. Özcan, B. Erdem, A. Özcan, Adsorption of acid blue 193 from aqueous solutions onto BTMA-bentonite, Colloids Surf. A Physicochem. Eng. Asp. 266 (2005) 73-81.

[38] I.K. Chandra, A.E. Angkawijaya, S.P. Santoso, S. Ismadji, F.E. Soetaredjo, Y.H. Ju, Solution equilibria studies of complexes of divalent metal ions with 2-aminophenol and 3,4-dihydroxybenzoic acid, Polyhedron 88 (2015) 29-39.

[39] S.P. Santoso, I.K. Chandra, F.E. Soetaredjo, A.E. Angkawijaya, Y.H. Ju, Equilibrium studies of complexes between $\mathrm{N}$-acetylcysteine and divalent metal ions in aqueous solutions, J. Chem. Eng. Data 59 (2014) 1661-1666.

[40] S. Lagergren, About the theory of so-called adsorption of soluble substances, K. Sven. vetensk. akad. handl. 24 (1898) 1-39.

[41] N. Ghasemi, P. Tamri, A. Khademi, N.S. Nezhad, S.R.W. Alwi, Linearized equations of pseudo second-order kinetic for the adsorption of $\mathrm{Pb}(\mathrm{II})$ on Pistacia atlantica shells, IERI Procedia 5 (2013) 232-237. 